\title{
Addiction to the Internet and Online Gaming
}

\author{
BRIAN D. NG, M.S. and PETER WIEMER-HASTINGS, Ph.D.
}

\begin{abstract}
As computer and Internet use become a staple of everyday life, the potential for overuse is introduced, which may lead to addiction. Research on Internet addiction has shown that users can become addicted to it. Addiction to the Internet shares some of the negative aspects of substance addiction and has been shown to lead to consequences such as failing school, family, and relationship problems.
\end{abstract}

\section{INTRODUCTION}

$\mathrm{I}$ NTERNET ADDICTION is not yet a DSM IV diagnosis, but its definition has been derived from DSM IV criteria for addiction and obsession. Young ${ }^{13}$ coined the term "Internet Addiction Disorder" listing diagnostic criteria, which many researchers refer to as a starting point. Researchers such as Young ${ }^{13}$ replace the word "substance" with "Internet" in their analysis of Internet addiction, concluding that similar symptoms such as tolerance, withdrawal, craving, and negative life consequences are present in Internet addiction as well. Research done by Walker ${ }^{12}$ would label Internet addiction an obsessive and compulsive behavior, based on its similarities to gambling addiction and compulsive shopping, since these disorders lack a chemical dependence. Still, very little is known about Internet addiction as a whole.

Early research was completed by Shotton, ${ }^{12}$ concluding that addicted computer users were mainly male introverts. A few years later, studies by Griffiths, ${ }^{3,4} \mathrm{O}^{\prime}$ Reilly, ${ }^{7}$ and Young ${ }^{13-16}$ found drastically different results. Their results revealed that dependent users were primarily middle-aged females on home computers, ${ }^{16}$ and anyone with Internet access could become addicted. 7 Email, chat, and the web are examples of applications used on the Internet whose nature has addictive properties. ${ }^{15}$ Young found that interactive "real-time" services such as internet relay chat (IRC; live chat where users socialize and discuss common topics) and multi-user domains (MUDS; text-based virtual worlds where social interaction is required) proved to be most addictive. Frequent users of IRC 8 "consider online relationships as real as face-to-face relationships." Moody ${ }^{6}$ found that high internet use (on IRC or email) is associated with high emotional loneliness. MUDS7 users "become absorbed in the activities and relationships that occur in them." When examined as an addictive substance, applications such as IRC and MUDS can be used to "withdraw or escape from negative evaluations and the stress of interpersonal relationships," 2 resulting in loss of control of time spent on the internet. Users who tried to cut back the time they spent on the Internet to avoid these addiction-related problems could not. Young concluded that users do become addicted and that there is a potential for more addictive applications in the future.

With the availability of three-dimensional (3D) graphics in games, it became possible to build 3D visual representations of the once text-only MUDS. Now, users are able to see and interact with others in virtual worlds. These massively multiplayer online role playing games (MMORPGs), such as "Everquest" and "Ultima Online," have been categorized as "heroinware" by many of its users, as they contain all of the addictive elements of IRC and MUDS. MMORPGs, which are run continuously in real time,

School of Computer Science, Telecommunications and Information Systems, DePaul University, Chicago, Illinois. 
feature social and competitive aspects, making devotion to the game mandatory. While traditional videogames end at some point or become repetitive and boring, MMORPGs are endless, because the main feature of MMORPGs is its system of goals and achievements. As you play, your character advances by gaining experience points "leveling up" from one level to the next, while collecting valuables and weapons-becoming wealthier and stronger. Social interaction in MMORPGs is highly essential, as you must collaborate with other players in the game to succeed in more complex goals. Eventually, a player must join a "guild" or "clan" of other players to advance further in the game.

Everquest (or Evercrack, as many players have nicknamed it) is a fantasy game, based on concepts similar to the work of Tolkien's Middle Earth. Because of its popularity, Everquest has received the most press and the most blame for MMORPG addiction. News.com ${ }^{1}$ quoted one recovering Everquest player, "The game almost ruined my life, it was my life. I ceased being me; I became Madrid, the Great Shaman of the North. Thinking of it now, I almost cringe; it's so sad." Another player explained his addiction, "I'd say the most addictive part for me was definitely the gain of power and status ..."

Young ${ }^{16}$ provided research that shows certain users become addicted to specific applications used on the internet. Griffiths ${ }^{4}$ concluded the same, with results showing that addicts are usually addicted to online chat or fantasy role-playing games (MUDS). Griffiths also emphasized that these applications allowed users an anonymity, allowing them to create their own social identities, raising the users' selfesteem. It is this anonymity that gives those with low self-confidence and lacking social skills the desire to create a virtual life for themselves on the Internet. In these cases, the Internet becomes a substitute for real-life social interaction, giving the user an escape from reality. ${ }^{15}$ In the early 1990s, the Internet addict was stereotyped as a male computer hobbyist, but recent research proves that anyone can become addicted, as it is a combination of personality type and Internet application that causes overuse leading into addiction.

\section{MATERIALS AND METHODS}

In this study, a comparison will be made between online MMORPG game users and offline video game users, to find elements that differentiate the two types of users and factors that contribute to overuse. It is proposed that factors which cause internet overuse are similar to those that cause MMORPG overuse.

The evaluations took place online in the form of two surveys which served to compare the two types of users. The surveys are based on a survey developed in 1999 by Pratarelli et al.,${ }^{9}$ which was devised to gather data on the behavioral patterns of heavy Internet users. This survey has been modified to explore the individuals who are primarily MMORPG or video game players (respectively, online and offline game players). To facilitate the comparison study, the same survey was used for the testing of both user groups, with the exception of the terms "MMORPG" and "video games." These two terms were replaced in the context of its respective test; this preserved the questions, yet changed the context. The survey questions were collected anonymously through an online survey, which was advertised on various gaming forums hosted on well-known gaming sites: www.eqvault.ign.com, www.everlore.com, and www.fohguild.org. After 10 days, the surveys were taken offline. Rewards were not offered to those who volunteered to participate. Questions are generalized so that any sample user from the general population who has played or plays MMORPGs or video games can answer. If a user was primarily a MMORPG player, they were asked to complete the MMORPG survey, and similarly for video game users.

Individual survey items gathered data on demographic information, game usage patterns, social behaviors of users, and the user's game purchasing habits. Demographic information collected was gender, educational level, professional level, hours per week spent playing games, and time of day spent playing. All remaining questions were Likert-scaled responses asking users to rank their agreement or disagreement to each question on a scale from 1 to 5. Game usage questions focused on how much time users were spending on games, how long a typical session would last, if usage time affected their daily schedules, and measured for indications of spending too much time using games. Social behavior questions collected data on dependence, companionship, self-image, and attitude of the user while gaming. Lastly, users answered questions about their game-purchasing habits.

\section{RESULTS}

The MMORPG survey demographics had a total of 91 responses: $88 \%$ of those were male, $44 \%$ had a high school degree, and $29 \%$ had a bachelor's degree; $37 \%$ were students while $53 \%$ worked as full- 
TAble 1. Hours Per WeEk Spent ON

GAMING BY MMORPG PLAYERS AND

NON-MMORPG Players IN PERCENTAGE

\begin{tabular}{lcc}
\hline Hours per week & $\begin{array}{c}\text { MMORPG } \\
\text { players }\end{array}$ & $\begin{array}{c}\text { Non-MMORPG } \\
\text { players }\end{array}$ \\
\hline $0-1 \mathrm{~h}$ & $1 \%$ & $11 \%$ \\
$1-2 \mathrm{~h}$ & $5 \%$ & $38 \%$ \\
$3-6 \mathrm{~h}$ & $10 \%$ & $35 \%$ \\
$7-10 \mathrm{~h}$ & $13 \%$ & $7 \%$ \\
$11-20 \mathrm{~h}$ & $25 \%$ & $2 \%$ \\
$21-40 \mathrm{~h}$ & $34 \%$ & $4 \%$ \\
40 or more $\mathrm{h}$ & $11 \%$ & $2 \%$ \\
\hline
\end{tabular}

time employees. When asked how many hours a week they spent on MMORPGs, 13\% spent 7-10 h, $25 \%$ spent $11-20 \mathrm{~h}, 34 \%$ spent $21-40 \mathrm{~h}$, and $11 \%$ spent $40+\mathrm{h}$ playing a week (see Table 1). Eightytwo percent played during the hours of 6 to 11 p.m.

Demographic data for video game users was quite similar to MMORPG users, as expected. Fortyeight responses were reported, and of those, $71 \%$ were male; $25 \%$ had a high school degree, while $54 \%$ had a bachelor's degree; $29 \%$ were students, whereas $71 \%$ were full-time employees. In contrast to the hours spent playing per week, video game users spent significantly less time playing their games per week: $38 \%$ played for $1-2 \mathrm{~h}$ a week, $35 \%$ spent $3-6 \mathrm{~h}$, and $6 \%$ spent $7-10 \mathrm{~h}$ a week; and $87 \%$ played during the hours of 6 to 11 p.m., which was similar to the MMORPG players.

Likert-scaled questions on game usage patterns, social behaviors of users, and game purchasing habits were analyzed with an unpaired $t$-test for significance between the two group's test results. According to the data on game usage patterns, six of the questions showed a high significance $(p=0.0001)$, two showed some significance, and two did not have any significance. MMOPRG players had tendencies of playing for $8 \mathrm{~h}$ continuously, losing sleep because of playing, and had been told they spend too much time playing (see Table 2). All questions that suggested heavy overuse were dominated by the MMOPRG users. Social behaviors of users varied for the two groups, as significance was found in $50 \%$ of the questions in this category. MMORPG users would rather spend time in the game than with friends, have more fun with in-game friends than people they know, found it easier to converse with people while in-game, did not find social relationships as important, and felt happier when in the game than anywhere else (see Table 3). Offline game users had sought out video games to alleviate depression at times, while MMORPG users did not. However, neither group used games as a diversion from loneliness or to gain self-confidence. Monetary spending on games between both groups showed no significance, as neither group had any monetary issues associated with gaming.

\section{DISCUSSION}

The findings confirm the background that has been presented and highlights the differences between the two groups. It is clear that MMORPG users have a tendency to spend many more hours devoted to their game and find the social aspects of the in-game world more pleasant and satisfying than what occurs in the real world. However, MMORPG users do not seek self-confidence in-game, would find fun elsewhere if MMORPGs did not exist, and would not feel irritated if they did not have the chance to play for 1 day. This would suggest that, as much as MMORPG users enjoy the time they spend in-game, even more so than real-life activities with friends, they are not addicted. I would propose that MMOPRG users have a different perspective on social life, which could be labeled as anti-social or introverted by most, and as such choose to spend their social time and energy in-game rather than socializing in the real world. It is the social aspects inherent in MMORPGs that draws in the

TABle 2. MMORPG Players AND NON-MMORPG Players Who Have Spent More Than Eight Continuous Hours Playing IN ONE SESSION

\begin{tabular}{lcc}
\hline Likert scaling & MMORPG players & Non-MMORPG players \\
\hline Strongly agree & $58 \%$ & $23 \%$ \\
Agree & $22 \%$ & $23 \%$ \\
Does not apply & $1 \%$ & $5 \%$ \\
Disagree & $10 \%$ & $18 \%$ \\
Strongly disagree & $9 \%$ & $32 \%$ \\
\hline
\end{tabular}


TABle 3. MMORPG Players AND NON-MMORPG Players Who Find It Easier to Talk to People While in Game Sessions

\begin{tabular}{lcc}
\hline Likert scaling & MMORPG players & Non-MMORPG players \\
\hline Strongly agree & $12 \%$ & $2 \%$ \\
Agree & $23 \%$ & $2 \%$ \\
Does not apply & $5 \%$ & $4 \%$ \\
Disagree & $34 \%$ & $47 \%$ \\
Strongly disagree & $25 \%$ & $47 \%$ \\
\hline
\end{tabular}

"hard-core" players who show patterns of addiction. For most users, it would seem that MMORPGs are an alternative to other forms of social entertainment. If MMORPGs were not available or did not exist, these same users would not seek friends or social situations such as parties, bars, or clubs, but perhaps other forms of socializing online in the form of email, chat rooms, or instant messenger. Since it is apparent that most users are not addicted, but rather choose to spend their time on MMORPGs than elsewhere, determining how they spend their time in-game could explain their attraction to the games. For future study, these social aspects and in-game activities could be explored in-depth. In conclusion, it is the social aspects that exist in-game that draw users into MMORPGs. Much like users who are addicted to the Internet, these gamers seek social experiences that are not available elsewhere in their lives. Even with high usage times, MMORPG users cannot be categorized as addicted, because they do not exhibit the behaviors of addicts.

\section{REFERENCES}

1. Becker, D. (2002). When games stop being fun [Online]. Available: http://news.com.com/2100-1040881673.html.

2. Craig, R. (1995). The role of personality in understanding substance abuse. Alcoholism Treatment Quarterly 13:17-27.

3. Griffiths, M.D. (1997). Psychology of computer use: XLIII. Some comments on "Addictive Use of the Internet." Psychological Reports 80:81-82.

4. Griffiths, M.D. (1998). Internet addiction: does it really exist? In: Gackenbach J. (ed.), Psychology and the Internet: intrapersonal, interpersonal, and transpersonal implications. San Diego: Academic Press, pp. 61-75.

5. Jacobson, D. (2001). Presence revisited: imagination, competence, and activity in text-based virtual worlds. CyberPsychology E Behavior 4:653-673.
6. Moody, E. (2001). Internet use and its relationship to loneliness. CyberPsychology \& Behavior 4:393-401.

7. O'Reilly, M. (1996). Internet addiction: a new disorder enters the medical lexicon. Canadian Medical Association Journal 154:188-189.

8. Peris, R. (2002). Online chat rooms: virtual spaces of interaction for socially oriented people. CyberPsychology \& Behavior 5:43-51.

9. Pratarelli, M., Browne, B., \& Johnson, K. (1999). The bits and bytes of computer/Internet addiction: a factor analytic approach. Behavior Research Methods, Instruments and Computers 31:305-314.

10. Shotton, M.A. (1991). The costs and benefits of "computer addiction." Behaviour Information and Technology 10:219-230.

11. Taylor, C. (2002). Lost in cyberspace. Time 159:21.

12. Walker, M.B. (1989). Some problems with the concept of "gambling addiction": should theories of addiction be generalized to include excessive gambling? Journal of Gambling Behavior 5:179-200.

13. Young, K. (1996). What makes the Internet addictive? potential explanations for pathological Internet use. Presented at the $105^{\text {th }}$ Annual Conference of the American Psychological Association, Chicago.

14. Young, K. (1996). Psychology of computer use: XL. Addictive use of the internet: a case that breaks the stereotype. Psychological Reports 79:899-902.

15. Young, K. (1996). Internet addiction: the emergence of a new clinical disorder. CyberPsychology E Behavior 1:237-244.

16. Young, K. (1998). Caught in the net: how to recognize the signs of Internet addiction - and a winning strategy for recovery. New York: John Wiley \& Sons.

Address reprint requests to: Brian David Ng, M.S.

School of Computer Science, Telecommunications, and Information Systems DePaul University 468 West $28^{\text {th }} \mathrm{Pl}$. Chicago, IL 60616

E-mail:bdng@sbcglobal.net 